Harvard Kennedy School Misinformation Review ${ }^{1}$

April 2020, Volume 1, Special Issue on COVID-19 and Misinformation

Creative Commons Attribution 4.0 International (ㄷ BY 4.0)

Reprints and permissions: misinforeview@hks.harvard.edu

DOI: https://doi.org/10.37016/mr-2020-014

Website: misinforeview.hks.harvard.edu

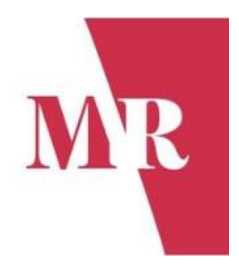

\title{
Identifying patterns to prevent the spread of misinformation during epidemics
}

This paper discusses patterns of public health misinformation observed during infectious disease epidemics. Specifically, we group epidemic-related misinformation into four categories: transmission, prevention, treatment, and vaccination. By developing tools, algorithms, and other resources around these categories, institutions, companies, and individuals can proactively limit and counter the spread of misinformation and its potential negative health effects.

Authors: Elaine O. Nsoesie (1), Olubusola Oladeji (1)

Affiliations: (1) School of Public Health, Boston University, USA

How to cite: Nsoesie, E. O., \& Oladeji, O. (2020). Identifying patterns to prevent the spread of misinformation during epidemics. Harvard Kennedy School (HKS) Misinformation Review, 1(3).

Received: April 3 $3^{\text {rd }}, 2020$. Accepted: April 23 ${ }^{\text {rd }}, 2020$. Published: April 27 2020.

\section{Four categories of public health misinformation in the time of COVID- 19}

Health misinformation (i.e., unsubstantiated claims about health and wellness in their many forms) has the potential to harm the public's health and is considered a major threat to global public health (Chou et al., 2018; Seymour et al., 2015). The framing and proliferation of health misinformation is motivated by many factors including the subject matter, the culture, and network dynamics. Studies suggest that the spread of misinformation varies by topic and that certain demographic groups and communities might be more susceptible to misinformation than others (Barthel et al., 2016; Törnberg, 2018; Vosoughi, et al., 2018). Misinformation is particularly destructive for vulnerable populations as they live in more precarious conditions. Additionally, individuals might be exposed to different types of misinformation based on their information-seeking patterns or due to data voids (Marwick \& Lewis, 2017; Nsoesie et al., 2020; Golebiewski \& Boyd, 2018). This is especially true during outbreaks of novel or emerging diseases, such as COVID-19 where much is unknown about the virus and vaccines or treatments do not yet exist.

It is difficult to quantify the impact that misinformation is having on efforts to control COVID-19 in countries around the world. While research linking misinformation to public health decision-making is emerging, there have been multiple past instances where misinformation has been associated with negative public health outcomes, including the spread of Ebola, and re-emergence of vaccine-preventable infectious diseases in the United States and Europe (Chou et al., 2018; Allgaier \& Svalastog, 2015; Oyeyemi

\footnotetext{
${ }^{1}$ A publication of the Shorenstein Center for Media, Politics and Public Policy, at Harvard University, John F. Kennedy School of Government.
} 
et al., 2014; Pathak et al., 2015; Roberts et al., 2017; Gyenes \& Mina, 2018; Larson, 2018). Misinformation about vaccines are usually linked to identity and beliefs, and can be considered chronic because they require continual attempts at correction (MacPherson, 2018). In contrast, most misinformation encountered during the COVID-19 pandemic can be classified as acute, meaning it can be corrected with scientific facts from trusted sources, such as the World Health Organization (WHO). However, whether acute or chronic, misinformation can lead to actions or changes in attitude that can impede the control of COVID-19 around the world. In an effort to better understand misinformation about COVID-19 and its consequences, we present a simple framework that can help us identify different types of misinformation related to COVID-19.

\section{Transmission}

False claims about how the COVID-19 virus spreads from person to person have been spreading since the start of the epidemic in China. There have been rumors that the new coronavirus is a bioweapon, or purposely released by the United States Army in China (Field \& Krzyzaniak, 2020; Myers, 2020). Analysis of the genome of the virus suggests that it was not constructed in a lab (Andersen et al., 2020). Some people have blamed people from China for spreading the virus, which has led to racist attacks and harassment (Tavernise \& Oppel, 2020). These claims are untrue. COVID-19 is an infectious disease that is mostly transmitted from person to person through droplets or discharge from an infected person's cough or sneeze. Any person who has not yet had the disease can become infected if they are exposed. While older people and those with pre-existing diseases such as chronic respiratory disease, cancer, diabetes, and cardiovascular diseases are more at risk of developing severe illness, any susceptible person can become infected when exposed to the virus (World Health Organization, 2020a).

Similar types of misinformation as those mentioned in the previous paragraph have been observed during other infectious disease outbreaks. For example, during the Zika epidemic in Brazil, there were misperceptions that the Zika virus was spread by genetically modified mosquitoes, and increases in microcephaly were due to larvicides in prenatal vaccines and drinking water (Carey et al., 2020; Venkatraman et al., 2016). Zika virus disease is transmitted by infected mosquitoes and was first identified in Uganda in 1947 (World Health Organization, 2018). Persons infected during pregnancy can give birth to infants with congenital Zika syndrome, which includes microcephaly and other congenital malformations. A difference between COVID-19 and Zika is that the coronavirus is new, and we are constantly learning new information about the virus. In fact, as a result of new information and our rapidly developing understanding of the virus, the general public can be confused and more susceptible to the influence of misinformation. For example, prior to studies showing that asymptomatic individuals might spread the coronavirus, it was assumed that asymptomatic individuals were not a major driver of spread based on what is known about other coronaviruses and influenza (Bai et al., 2020; Rothe et al., 2020).

\section{Prevention}

Misinformation on prevention tends to focus on encouraging or promoting certain behaviors claiming they will stave off infection. For example, misinformation on WhatsApp claims that eating onions or alligator peppers multiple times a day will prevent coronavirus infection. Although onions and alligator peppers have nutritional value, the claims that these spices can prevent coronavirus disease is false. These types of misinformation might appear harmless but could have negative effects on health for several reasons. People who believe these claims might refrain from following scientifically supported preventative recommendations from the WHO or other trusted sources because of the assumption that 
these claims are sufficient on their own. These types of misinformation tend to spread within networks of friends and family on WhatsApp and other digital platforms. If not addressed, harmful information spread by the same sources can lead to more severe health impacts.

\section{Treatments}

The Food and Drug Administration (FDA) has issued warnings to companies against selling medications falsely claiming to treat or prevent COVID-19 (FDA U.S. Food \& Drug Administration, 2020). The specific products mentioned include colloidal silver, chlorine dioxide products, tinctures, teas, and essential oils (FDA U.S. Food \& Drug Administration, 2020). Such warnings by the FDA are critical in stopping the spread of misinformation and the potential negative health effects that erroneous treatments can produce. For example, during the Ebola epidemic in West Africa, at least two people died in Nigeria after drinking salt water, which was purported as a treatment for the disease (Onyeonoro et al., 2015; World Health Organization, 2014). Similarly, misinformation distributed on digital platforms during the Yellow fever epidemic in Brazil claimed that the illness could be cured by consuming certain medicinal plants such as the pawpaw fruits, cinchona officinalis, or using homeopathic treatments (Ortiz-Martínez \& JiménezArcia, 2017). People who rely on such unfounded treatments can delay seeking verified medical services which can lead to more severe manifestations of the disease or death.

\section{Vaccination}

Vaccines can prevent illness or reduce the risk of severe illness (Centers for Disease Control and Prevention, 2019). However, we choose to discuss vaccine misinformation separately from prevention because we do not yet have a vaccine against COVID-19. In a study characterizing Zika vaccine misinformation, the authors noted that the lag time it takes for vaccine development and approval can mislead and spread unnecessary fear and skepticisms on vaccines which can lead to vaccine refusal (Dredze et al., 2016). Although vaccines are not yet available for COVID-19, there are already conspiracy theories on social media platforms that claim vaccines are meant to spread the disease. Similar misinformation has been observed during other epidemics. During the Zika epidemic in the Americas, people seemed to have an increased interest in pseudo-scientific theories on the Zika vaccine. These theories unfortunately reinforced already held beliefs about the dangers of vaccines even though a vaccine was not available (Centers for Disease Control and Prevention, 2019). Vaccine misinformation, which has become a politicized issue, especially in high-income countries is aided by bots (i.e., accounts that use algorithms to produce automated content) and trolls (i.e., individuals who post provocative content under obscured identities) and has been shown to impede the control of disease outbreaks (Broniatowski et al., 2018).

\section{Challenge and conclusions}

Automated approaches that limit the spread of all types of misinformation during epidemics do not exist. This is partly because the scale and prevalence of health misinformation on the Internet is unknown (Chou et al., 2018). Information about transmission, prevention, treatments, and vaccines can also change over the course of an epidemic as has been observed during the COVID-19 pandemic, making it more difficult to target and correct. Misinformation can also be shared by trusted sources, including scientists, news outlets, and government officials, particularly when confronted with new and unfamiliar diseases. 
Furthermore, the framing and dissemination of various types of health misinformation can change rapidly as major actors adapt to new regulations and policies. For example, as platforms such as WhatsApp, develop approaches to limit the spread of misinformation, major actors can move to other platforms with less regulation. Also, as treatments are tested via clinical trials, the framing of misinformation about treatments in some cases has shifted from the promotion of unverified medications to treat disease to claims about the potential effectiveness of treatments under evaluation.

Social media platforms have widened the opportunity to access and share proven health information and misinformation. Therefore, effective tools are needed for monitoring and quantifying the extent of health misinformation on different platforms. One way of addressing this is the current approach of recognizing the different types of misinformation and designing educational, ethical, and computational interventions to reduce the spread. For instance, Google, Facebook, and other tech companies are taking actions to combat misinformation by promoting credible information and removing misinformation from their platforms (Jin, 2020; Shu \& Shieber, 2020). WhatsApp has also limited the ease of forwarding messages on its platform (Kazeem, 2020). Interventions focused on identifying and removing misinformation from social media platforms could be more effective if they incorporate details on patterns of misinformation during epidemics. For example, it is important to understand that there are similarities and differences in the framing of misinformation on transmission, prevention, treatment, and vaccination. These differences could aid algorithms designed to automate the identification and removal of misinformation from such platforms.

Another approach to addressing misinformation is active education of the public by providing verified information to populations most affected. For example, WhatsApp has collaborated with WHO and other health organizations to develop bots for sharing the latest developments and accurate information. The WHO chatbot responds to numbers and text. For example, texting "hi" to +41798931892 on WhatsApp will provide the full menu, which includes information on protection, myths, and travel advice (World Health Organization, 2020b). Texting "1" to this number will provide up-to-date statistics on COVID-19. The WHO also has a myth busters webpage that addresses misinformation about COVID-19 as it emerges (World Health Organization, 2019). While these tools are necessary and valuable, tech and public health experts need to be more proactive in educating vulnerable populations. This requires developing contextualized approaches that take advantage of cultural and social values.

Lastly, it is also important to increase the public's understanding of the possible adverse health effects of misinformation (Snyder \& Cohen, 2019). Health misinformation should be incorporated into digital education curriculum to educate the public on how to find, assess, validate, and corroborate information from trusted sources before adopting recommendations seen on social media platforms. While the public can play a major role in limiting the impact of misinformation on the spread of epidemics, the responsibility to lessen the effects of health misinformation should never be left solely to the individual.

\section{Bibliography}

Allgaier, J., \& Svalastog, A. L. (2015). The communication aspects of the Ebola virus disease outbreak in Western Africa - do we need to counter one, two, or many epidemics? Croatian Medical Journal, 56(5), 496-499. https://doi.org/10.3325/cmj.2015.56.496

Andersen, K. G., Rambaut, A., Lipkin, W. I., Holmes, E. C., \& Garry, R. F. (2020). The proximal origin of SARS-CoV-2. Nature Medicine, 26, 450-452. https://doi.org/10.1038/s41591-020-0820-9

Bai, Y., Yao, L., Wei, T., Tian, F., Jin, D. -Y., Chen, L., \& Wang, M. (2020). Presumed asymptomatic carrier transmission of COVID-19. JAMA, 323(14), 1406-1407. https://doi.org/10.1001/jama.2020.2565 
Barthel, M., Mitchell, A., \& Holcomb, J. (2016). Many Americans believe fake news is sowing confusion. Pew Research Center. https://www.journalism.org/wpcontent/uploads/sites/8/2016/12/PJ 2016.12.15 fake-news FINAL.pdf

Broniatowski, D. A., Jamison, A. M., Qi, S., AlKulaib, L., Chen, T., Benton, A., Quinn, S. C., \& Dredze, M. (2018). Weaponized health communication: Twitter bots and Russian trolls amplify the vaccine debate. American Journal of Public Health, 108(10), 1378-1384. https://doi.org/10.2105/AJPH.2018.304567

Carey, J. M., Chi, V., Flynn, D. J., Nyhan, B., \& Zeitzoff, T. (2020). The effects of corrective information about disease epidemics and outbreaks: Evidence from Zika and yellow fever in Brazil. Science Advances, 6(5). https://doi.org/10.1126/sciadv.aaw7449

Centers for Disease Control and Prevention. (2019, March 18). Vaccines for your children. https://www.cdc.gov/vaccines/parents/index.html

Chou, W. -Y. S., Oh, A., \& Klein, W. M. P. (2018). Addressing health-related misinformation on social media. JAMA, 320(23), 2417-2418. https://doi.org/10.1001/jama.2018.16865

Dredze, M., Broniatowski, D. A., \& Hilyard, K. M. (2016). Zika vaccine misconceptions: A social media analysis. Vaccine, 34(30), 3441-3442. https://doi.org/10.1016/i.vaccine.2016.05.008

FDA U.S. Food \& Drug Administration (2020). Press announcements - health fraud. https://www.fda.gov/consumers/health-fraud-scams/press-announcements-health-fraud

Field, M., \& Krzyzaniak, J. (2020, March 19). Why do politicians keep breathing life into the false conspiracy theory that the coronavirus is a bioweapon? Bulletin of the Atomic Scientists. https://thebulletin.org/2020/03/why-do-politicians-keep-breathing-life-into-the-falseconspiracy-theory-that-the-coronavirus-is-a-bioweapon/

Golebiewski, M., \& Boyd, D. (2018). Data voids: Where missing data can easily be exploited. Data \& Society. https://datasociety.net/wpcontent/uploads/2018/05/Data Society Data Voids Final 3.pdf

Gyenes, N., \& Mina, A. X. (2018, August 30). How misinfodemics spread disease. The Atlantic. https://www.theatlantic.com/technology/archive/2018/08/how-misinfodemics-spreaddisease/568921/

Jin, K. -X. (2020, October 5). Keeping people safe and informed about the coronavirus. Facebook. https://about.fb.com/news/2020/10/coronavirus/

Kazeem, Y. (2020, April 7). WhatsApp is limiting message forwarding as coronavirus misinformation takes hold in Africa. Quartz Africa. https://qz.com/africa/1834095/coronavirus-whatsappclamps-down-on-message-forwarding/

Larson, H. J. (2018). The biggest pandemic risk? Viral misinformation. Nature, 562, 309-310. https://doi.org/10.1038/d41586-018-07034-4

MacPherson, Y. (2018, December 17). The truth about health misinformation: It's not just about fact checking. BBC Media Action Insight Blog. https://www.bbc.co.uk/blogs/mediaactioninsight/entries/d86fcdde-5420-4973-99bf$\underline{59136 a 3 b c 222}$

Marwick, A., \& Lewis, R. (2017). Media manipulation and disinformation online. Data \& Society. http://www.chinhnghia.com/DataAndSociety MediaManipulationAndDisinformationOnline.pdf

Myers, S. L. (2020, March 17). China spins tale that the U.S. army started the coronavirus epidemic. The New York Times. https://www.nytimes.com/2020/03/13/world/asia/coronavirus-chinaconspiracy-theory.html

Nsoesie, E. O., Oladeji, O., \& Sengeh, M. D. (2020). Digital platforms and non-communicable diseases in sub-Saharan Africa. The Lancet Digital Health, 2(4), e158-e159. https://doi.org/10.1016/S2589$\underline{7500(20) 30028-5}$ 
Onyeonoro, U. U., Ekpemiro, U. C., Abali, C., \& Nwokeukwu, H. I. (2015). Ebola epidemic - the Nigerian experience. The Pan African Medical Journal, 22(1), 17.

https://doi.org/10.11694/pamj.supp.2015.22.1.6625

Ortiz-Martínez, Y., \& Jiménez-Arcia, L. F. (2017). Yellow fever outbreaks and Twitter: Rumors and misinformation. American Journal of Infection Control, 45(7), 816-817. https://doi.org/10.1016/j.ajic.2017.02.027

Oyeyemi, S. O., Gabarron, E., \& Wynn, R. (2014). Ebola, Twitter, and misinformation: A dangerous combination? British Medical Journal, 349, g6178. https://doi.org/10.1136/bmi.g6178

Pathak, R., Poudel, D. R., Karmacharya, P., Pathak, A., Aryal, M. R., Mahmood, M., \& Donato, A. A. (2015). YouTube as a source of information on Ebola virus disease. North American Journal of Medical Sciences, 7(7), 306-309. https://doi.org/10.4103/1947-2714.161244

Roberts, H., Seymour, B., Fish, S. A., Robinson, E., \& Zuckerman, E. (2017). Digital health communication and global public influence: A study of Ebola epidemic. Journal of Health Communication, 22(sup1), 51-58. https://doi.org/10.1080/10810730.2016.1209598

Rothe, C., Schunk, M., Sothmann, P., Bretzel, G., Froeschl, G., Wallrauch, C., Zimmer, T., Thiel, V., Janke, C., Guggemos, W., Seilmaier, M., Drosten, C., Vollmar, P., Zwirglmaier, K., Zange, S., Wölfel, R., \& Hoelscher, M. (2020). Transmission of 2019-nCoV infection from an asymptomatic contact in Germany. New England Journal of Medicine, 382(10), 970-971. https://doi.org/10.1056/NEJMc2001468

Seymour, B., Getman, R., Saraf, A., Zhang, L.H., \& Kalenderian, E. (2015). When advocacy obscures accuracy online: Digital pandemics of public health misinformation through an antifluoride case study. American Journal of Public Health, 105(3), 517-523. https://doi.org/10.2105/AJPH.2014.302437

Shu, C., \& Shieber, J. (2020, March 16). Facebook, Reddit, Google, LinkedIn, Microsoft, Twitter and YouTube issue joint statement on misinformation. TechCrunch. https://techcrunch.com/2020/03/16/facebook-reddit-google-linkedin-microsoft-twitter-andyoutube-issue-joint-statement-on-misinformation/

Snyder, J., \& Cohen, I. G. (2019). Medical crowdfunding for unproven medical treatments: Should Gofundme become a gatekeeper? The Hastings Center Report, 49(6), 32-38. https://doi.org/10.1002/hast.1066

Tavernise, S., \& Oppel, R. A. (2020, March 23). Spit on, yelled at, attacked: Chinese-Americans fear for their safety. The New York Times. https://www.nytimes.com/2020/03/23/us/chinesecoronavirus-racist-attacks.html

Törnberg, P. (2018). Echo chambers and viral misinformation: Modeling fake news as complex contagion. PLoS One, 13(9), 1-21. https://doi.org/10.1371/journal.pone.0203958

Venkatraman, A., Mukhija, D., Kumar, N., \& Nagpal, S. J. S. (2016). Zika virus misinformation on the internet. Travel Medicine and Infectious Disease, 14(4), 421-422. https://doi.org/10.1016/i.tmaid.2016.05.018

Vosoughi, S., Roy, D., \& Aral, S. (2018). The spread of true and false news online. Science, 359(6380), 1146-1151. https://doi.org/10.1126/science.aap9559

World Health Organization. (2014, August 15). Ebola: Experimental therapies and rumoured remedies. https://www.who.int/mediacentre/news/ebola/15-august-2014/en/

World Health Organization. (2018, July 20). Zika virus. https://www.who.int/news-room/factsheets/detail/zika-virus

World Health Organization. (2019). Coronavirus disease (COVID-19) advice for the public: Myth busters. https://www.who.int/emergencies/diseases/novel-coronavirus-2019/advice-for-public/mythbusters 
World Health Organization. (2020a). Coronavirus. https://www.who.int/healthtopics/coronavirus\#tab=tab 1

World Health Organization. (2020b, March 20). WHO health alert brings COVID-19 facts to billions via WhatsApp. https://www.who.int/news-room/feature-stories/detail/who-health-alert-bringscovid-19-facts-to-billions-via-whatsapp 


\section{Copyright}

This is an open access article distributed under the terms of the Creative Commons Attribution License, which permits unrestricted use, distribution, and reproduction in any medium, provided that the original author and source are properly credited. 